\title{
COMPETÊNCIAS EMPREENDEDORAS DE DIRIGENTES QUE LIDERAM EMPRESAS DE JOGOS MOBILE NO ARRANJO CRIATIVO PORTOMÍDIA
}

Moisés De Assis Alves Soares ${ }^{1}$

Fernando Paiva Júnior ${ }^{1}$

Chris Herbert Berenguer Pereira ${ }^{2}$

${ }^{1}$ Universidade Federal de Pernambuco - UFPE

${ }^{2}$ Centro de Ciências Sociais Aplicadas / UNIVERSIDADE DE PERNAMBUCO 


\section{COMPETÊNCIAS EMPREENDEDORAS DE DIRIGENTES QUE LIDERAM EMPRESAS DE JOGOS MOBILE NO ARRANJO CRIATIVO PORTOMÍDIA}

Resumo: O estudo objetiva compreender as competências empreendedoras do comportamento de dirigentes de empresas desenvolvedoras de jogos mobile. O lócus de investigação é o Arranjo produtivo Portomídia, integrante do Porto Digital, voltado para qualificação, empreendedorismo, educação, experimentação e exibição que contempla pequenas e médias empresas especializadas em transformar criações em produtos e serviços voltados à promoção da economia criativa na cidade do Recife. O estudo é de caráter qualitativo e descritivo contemplando estratégia de estudo de caso múltiplo incorporado, a partir de uma análise de conteúdo temática desenvolvida com dados obtidos por entrevistas semiestruturadas realizadas junto a dirigentes das empresas de jogos móveis. Os resultados revelam que as competências empreendedoras contribuem para o processo de negociação entre os agentes envolvidos nessa produção, o que permite a aderência a certas exigências do mercado de consumo e expressa o esforço multifuncional que perpassa a ação inovadora desse tipo de empreendedor.

Palavras-chave: empreendedorismo digital. competências empreendedoras. Jogos Mobile. Portomídia.

\section{Introdução}

As novas tecnologias digitais têm transformado a natureza e formas de lidar com a incerteza inerente aos processos e resultados empresariais contemporâneos, o que conduz a questões primordiais na interseção de tecnologias digitais e empreendedorismo, o que pode constituir a era do empreendedorismo digital. Com isso, surgem implicações de processos e resultados empresariais menos limitados por fronteiras de agência empresarial e a promoção uma agenda de pesquisa que exige a teorização explícita de conceitos relacionados às tecnologias digitais articuladas com as práticas empreendedoras. Ao articular a promessa e o valor dessa perspectiva da tecnologia digital, consideramos como ela tem potencial de enriquecer as teorias existentes de empreendedorismo (NAMBISAN, 2017; VON BRIEL; DAVIDSSON; RECKER, 2018).

Os novos mercados surgem com iniciativas abertas para integralizar um ecossistema inteligente, dinâmico e competitivo que estimula o empreendedor a buscar várias formas de aprender e desenvolver habilidades inerentes através das tecnologias de informação e comunicação (TIC) e de conteúdos digitais apresentados a cada momento imposto pela nova economia (LAMERAS et al., 2015). No que tange à evolução de práticas empreendedoras, a paisagem do empreendedorismo tradicional vem sofrendo mudanças significativas com o resultado de inovações orientadas para a tecnologia. Assim , a disseminação das tecnologias móveis e sua apropriação pela sociedade contemporânea (EDWARDS-SCHACHTER et al. 2015) fez com que dirigentes do setor de jogos mobile começassem a buscar novas formas de potencializar suas atividades empreendedoras no universo digital.

Por ser o mercado de jogos mobile complexo, dinâmico e repleto de incertezas, os dirigentes dessas empresas são obrigados a tomar decisões frequentes no sentido de adaptar as
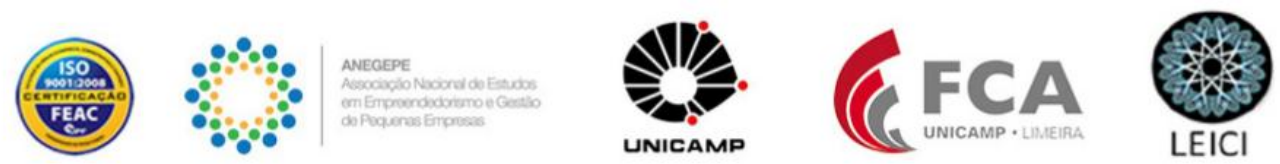
ações de suas equipes a situações imprevisíveis. Uma forma de adaptação bem sucedida para a indústria de jogos eletrônicos foi a evolução do processo de desenvolvimento desses games para plataformas móveis com uso de dispositivos portáteis (gadgets), a exemplo de tablets, celulares e smartphones, o que resultou numa mudança de comportamento de base, ações e conhecimento (FUNG, 2017).

As constantes mudanças de comportamento dos usuários resultam em diferentes demandas operacionais, exigindo, por parte dos dirigentes, capacidade observacional e aprendizado constante. Por conseguinte, essas práticas devem ser vistas como um processo contínuo voltado para o desenvolvimento de competências que visam a aquisição de qualificação empreendedora, profissional e certificável (PARKER; COX; THOMPSON, 2014).

A prática profissional presente nos negócios voltados para inovação está associada a competências que são potencializadas em ambientes empreendedores. Autores como Abatecola (2016), Edwards-Schachter et al. (2015) e Mietzner e Kamprath (2013) as definem como capacidades de auto-organização que ocorrem em situações problemáticas e de decisões abertas em sistemas complexos. Por isso, elas são vistas como características subjacentes ao desempenho eficaz de líderes criativos (GALANAKIS; GIOURKA, 2017).

$\mathrm{O}$ desempenho de competências protagonizadas por agentes oriundos do ecossistema produtivo da indústria de jogos mobile ilustra o nível de desenvolvimento do capital intelectual, que influencia suas ações em grau de conhecimento, criatividade ou habilidades. Nesse contexto, o empreendedor manifesta a capacidade de operacionalizar e estruturar as competências necessárias a um modo de qualificação que cumpra com eventuais exigências de atividade intensiva em tecnologia (LELOUX; POPESCU; KOOPS, 2017).

As competências empreendedoras, reconhecidas como saber prático especializado, denotam um conhecimento técnico direcionado para a formação diferenciada daquele profissional preparado para atender demandas que emergem de um segmento de mercado tecnológico, criativo e inovador e despontam em torno de uma linha de tendências de crescimento e interesse em explorar o mercado de jogos mobile, proeminente de uma nova economia de negócios (GAO; KROGSTIE; ZANG, 2016).

Novos negócios estão imersos nas chamadas Indústrias Criativas (HARTLEY, 2005), que crescem em ritmo acelerado devido às possibilidades de distribuição digital advindas de avanços nas tecnologias da informação e comunicação, passando a influenciar aspectos comportamentais dos consumidores de videogames ao redor do globo (ROMERO, USART \& OTT, 2014; SEOK \& DACOSTA, 2015). As demandas crescentes por produtos de entretenimento digital abrem portas de entrada para profissionais especializados, sobretudo, na produção de jogos mobile (MIETZNER; KAMPRATH, 2013).

A maneira como o indivíduo articula seus recursos para enfrentar situações de sua vida pessoal e profissional tende a resultar no desenvolvimento de técnicas e ferramentas que auxiliam seu preparo diante de adversidades mercadológicas (ZARIFIAN, 2001). Nesse sentido, a competência empreendedora se configura em ações repletas de conhecimento inato que permitem ao empreendedor se "blindar" para manter-se no mercado. Nessa ótica e contemplando suas competências, o empreendedor enfrenta desafios relacionados à busca por solução de problemas complexos atrelados ao seu cotidiano profissional. Desse modo, a

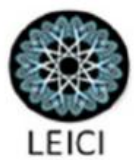


execução do estudo se pauta pela seguinte pergunta de pesquisa: Que competências empreendedoras emergem do comportamento de líderes que dirigem empresas de jogos mobile no Arranjo Portomídia?

\section{Competências Empreendedoras em Empresas de Jogos Mobile}

$\mathrm{O}$ mercado dos games exige que o empreendedor desenvolva sua prática profissional com base na ação investigativa no âmbito de um contexto tecnológico de habilidadecompetência-aprendizagem. A modalidade de aprendizagem desse tipo de empreendorismo digital está demarcada por sua ação articulada em redes sociais e nas suas percepções acerca de a realidade empresarial e tecnológica que constitui o mercado de jogos. Portanto, é primordial a construção do diálogo sobre as competências empreendedoras, no mercado de jogos mobile leva ao conhecimento crítico, imbricado com os processos de inovação e criatividade (KOIVISTO; MERILAMPI; SIRKKA, 2015).

Do bojo das competências alvo deste estudo, originam-se conceitos de estudos que subsidiam a literatura do empreendedorismo, trazendo uma discussão que questiona abordagens gerenciais tradicionais de gestão empreendedora em oposição àquelas que contemplam práticas de aventura empresarial visíveis na sociedade da informação e conhecimento, mediadas por tecnologias da era digital (NAMBISAN, 2017; VON BRIEL; DAVIDSSON; RECKER, 2018). Nesse contexto, pensamos em competências empreendedoras presentes no comportamento de dirigentes do universo de empresas produtoras de jogos mobile, como sendo referência do empreendedorismo digital - definido sob a égide da capacidade do empreendedor contemporâneo de acessar, criar, processar e divulgar estrategicamente competências emergentes nas sociedades de informação e conhecimento, caracterizada por livres fluxos de informação, conteúdos difíceis de serem protegidos e modelos de empreendimentos sustentáveis em ecossistemas que operam em plataformas digitais (DAVIDSON; VAAST, 2010; SUSSAN; ACS, 2017).

Os conceitos de competências empreendedoras fundamentam a base teórica em torno de inquietações relacionadas a paradigmas consolidados no cotidiano de dirigentes de empresas produtoras de jogos mobile (MAN; LAU, 2000; MELLO; LEÃO; PAIVA JÚNIOR, 2006). Por conseguinte, os empreendedores desse segmento se defrontam com a necessidade de adquirir conhecimentos especializados em práticas de gestão voltadas para projetos de cunho tecnológico (FUNG, 2017). É nesse contexto sociocultural e econômico que o empreendedor integra atributos oriundos de suas competências para incentivar na potencialização de um ambiente de inovação e criatividade, no qual suas atividades são evidenciadas com autoria, proatividade e integração automática (JAIN, 2011).

A proatividade envolve o ato de agir com antecipação frente ao mercado, moldar-se a repentinas mudanças do ambiente interno e externo, buscar vantagem competitiva e introduzir. (PARKER; BINDL, 2016; ERTURKOGLU; ZHANG; MAO, 2015). Logo, o empreendedor digital é tipicamente proativo, pois tem peculiaridades de um indivíduo que age de maneira distinta em situações similares e executa suas atividades individuais com destreza para alcançar suas metas e obter resultados positivos, apesar da existência de fatores hostis do setor, a exemplo da mudança repentina de comportamento do consumidor que causa oscilação

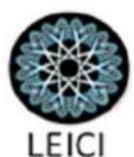


e incerteza para o mercado (GAO; KROGSTIE; ZANG, 2016; KOIVISTO; MERILAMPI; SIRKKA, 2015).

\section{Procedimentos Metodológicos}

A pesquisa do estudo é qualitativa e pautada pela análise das expressões humanas presentes nas relações sociais, nos sujeitos e nas representações, o que permite conhecer o objeto de pesquisa a partir da interpretação dos agentes sob a perspectiva do contexto da ação, sobre as ações em si e com respeito a seus resultados (CRESWELL, 2010; LEFÈVRE; LEFÈVRE, 2005). Portanto, o alcance do objetivo proposto conta com um estudo de caso múltiplo incorporado (YIN, 2005) sob a forma de pesquisa descritiva com a finalidade de fazer uma descrição e interpretação dos dados empíricos (LAKATOS, MARCONI, 2010; MINAYO, 2010).

Dentre as variações do estudo de caso, foi selecionado nesse formato de estudo o caso incorporado, em que num caso único, a atenção é destinada a várias subunidades (YIN, 2005). Selecionamos, assim, o Arranjo Criativo Portomídia como o caso de estudo, tendo como subunidades de análise, as empresas desenvolvedoras de jogos mobile ali instaladas. Nesse aspecto, os sujeitos da pesquisa são os dirigentes que atuam nessas empresas instaladas no Portomídia, em Recife, capital do estado de Pernambuco.

Foram realizadas entrevistas semi-estruturadas junto a dois dirigentes de empresas do setor de jogos mobile, as quais possibilitaram o conjunto de informações que ressaltaram características chave dos informantes. Tais informações serviram como instrumentos de análise dos processos de gestão empreendedora no universo digital. Logo, a figura 1 indica as iniciais dos dirigentes que integraram o estudo em que foram utilizados somente as iniciais dos nomes dos entrevistados para preservar suas identidades.

Após a coleta dos dados qualitativos e a transcrição das entrevistas realizadas, foi utilizado como suporte o software NVIVO em sua versão 8.0. que auxiliou na codificação dos dados, seleção das unidades de significado suas categorias de base para a análise dos dados. Por se tratar de um software de informação qualitativa, o processo de codificação do NVIVO facilitou no processo analítico do material coletado para garantir o esforço de interpretar os dados. O NVIVO (Versão 8.0) foi utilizado juntamente com uma abordagem indutiva sob a análise temática (BARDIN, 2011).

A análise de conteúdo foi efetuada com base em categorias para análise temática (BARDIN, 2011; MINAYO, 2010), que desmembra o texto em unidades e subunidades que priorizam aspectos referentes à dimensão de competências empreendedoras (MAN; LAU, 2000). E para se garantir a validade e credibilidade dos resultados, foi utilizada a técnica de triangulação (PAIVA JÚNIOR; LEÃO; MELLO, 2011. Assim, surgiram temas comuns a outros mercados, típicas de empreendimentos intensivos em tecnologia.

\section{As Empresas de Jogos Mobile domiciliadas no Arranjo Criativo Portomídia}

A Empresa E1 é um estúdio de produção de jogos mobile fundado em 2005 com a visão de criar e vender esses jogos para clientes em todo o mundo e trabalhando com as principais marcas de entretenimento. Hoje, eles têm mais de 100 jogos criados para diferentes

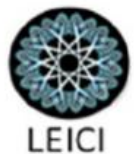


plataformas, gêneros e audiências. A equipe é formada por especialistas com bacharelado, mestrado e doutorado nas áreas de desenvolvimento de jogos.

A Empresa E2 foi fundada em 2012, na cidade de Recife. É um estúdio de desenvolvimento de jogos mobile que tem o objetivo de criar jogos free-to-play (gratuitos para jogar) para o jogador casual dedicado. Os jogos produzidos pela empresa combinam a acessibilidade e apelo em massa de jogos casuais com o elevado potencial de retenção e monetização de jogos mobile.

O Portomídia é identificado como um Arranjo Produtivo Local de Economia Criativa que tem o objetivo de promover o desenvolvimento socioeconômico local e fruto de uma iniciativa do Porto Digital que fomenta as práticas inovadoras e empreendedoras através das empresas de tecnologia de informação e comunicação (TIC), corroborando com a troca de conhecimento entre startups, aceleradoras e incubadoras de empresas.

Sendo um desdobramento do Porto Digital, o Portomídia foi criado em 2013 com a finalidade de contemplar pequenas e médias empresas especializadas em transformar criações em produtos e serviços voltados para a promoção da Economia Criativa. Logo, o Arranjo reside num projeto que oferece infra-estrutura, junto a um braço de qualificação, empreendedorismo e exibição, com o intuito de desenvolver estratégias que possibilitem projetar "a cidade nacional e internacionalmente como um centro de referência neste novo segmento da economia do conhecimento" (PORTO DIGITAL, 2017, p. 1). Esse Arranjo está dimensionado em quatro pilares, que são: capacitação, incubação, experimentação e demonstração (PORTOMÍDIA, 2015) e envolve os atores do governo, da academia e do mercado, oferecendo infra-estrutura e programas de qualificação com a finalidade de promover o desenvolvimento de novos modelos de negócios e criação de produtos de natureza transmídia que façam uso intensivo das TIC (ANDRADE et al., 2014).

\section{As Competências Empreendedoras de dirigentes de Empresas de Jogos Mobile}

As evidências empíricas relativas aos dirigentes que atuam em empresas desenvolvedoras de jogos mobile e referências do Portomídia (Arranjo Produtivo de Economia Criativa) desvelam dimensões de competências empreendedoras apresentadas por Man e Lau (2000) e Mello, Leão e Paiva Júnior (2006), tais como oportunidade, relacionamento, conceitual, estratégica, administrativas, de comprometimento e de equilíbrio entre o trabalho e a vida pessoal . A visão geral das competência, inclui conhecimentos individuais, habilidades e comportamentos, atrelados à alta performance que provê vantagem competitiva à organização.

\subsection{Dimensão das Competências de Oportunidade}

A busca por oportunidades é uma característica subjacente ao empreendedor de negócios intensivos em tecnologia, relacionada ao seu desempenho na realização de uma ação inovadora ou de situação que se diferencia de aptidões naturais de uma pessoa. Essa iniciativa refere-se à ideia ou proposta de nascimento de um negócio com potencial de sucesso a partir de um levantamento intencionado ao comportamento do mercado interno e/ou externo. Portanto, tal capacidade de antecipação aos fatos é o ponto de partida para se desenvolver uma ideia de negócio exitoso. Isso antecedido pelo estudo prévio das possibilidades de
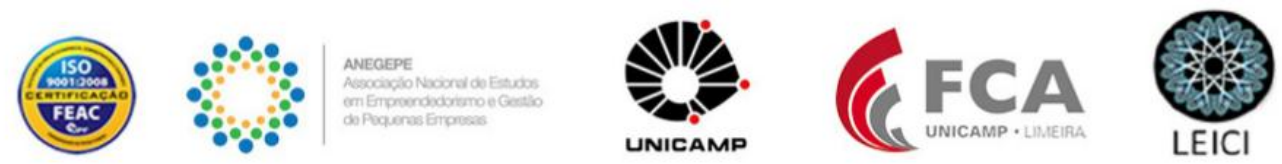
consolidar a absorção da oportunidade pela gestão empreendedora dos recursos disponíveis no empreendimento em conjunto com acessados na rede de negócios daquele empresário.

A identificação de oportunidades reside no reconhecimento de cenários benignos emergentes nos mercados de jogos que podem ser melhor explorados com o suporte da qualificação formal do empreendedor de jogos mobile, por experiências profissionais e pessoais vivenciadas nesse ramo de atividade durante sua formação acadêmica ou técnica naquele tipo de mercado ou pela absorção do conhecimento advindo de pesquisas acadêmicas oriundas de universidades e institutos de pesquisa (ALBUQUERQUE; TEIXEIRA, 2016). Por isso, a identificação das oportunidades de negócios está atrelada às experiências prévias do empreendedor, conforme ilustrado no relato a seguir:

Eu como jogador já conhecia muito esse ramo e minha formação acadêmica foi totalmente direcionada para desenvolvimento de jogos. Então, após aprender na prática a desenvolver jogos no Curso de Ciência da Computação, imediatamente tentamos criar um jogo nosso pra vender e distribuir no mercado, até que percebemos que três estudantes de Computação não iriam ter as habilidades necessárias pra criar o design de um jogo com uma experiência lúdica legal, mas, ao mesmo tempo conseguimos criar processos de desenvolvimentos de jogos que terminaram nos ajudando a transformar a Empresa no que ela é hoje (E1 - p.1) [grifo nosso].

Com relação às competências conceituais desenvolvidas pelos dirigentes voltados para o reconhecimento oportunidades de negócios, a expertise emerge em função da formação acadêmica e de procedimentos técnicos apreendidos e praticados pelos dirigentes em sua carreira profissional. Assim, o comentário do empreendedor corrobora com o estudo de Baden-Fuller e Haefliger (2013), quando afirmam que a composição de experiências associadas ao conhecimento técnico desenvolvido na academia passa por um momento de idealização do negócio até atingir o estágio da autoconfiança do empreendedor. Tal confiança vai se ampliando ao passo que vão surgindo parcerias com o mesmo potencial de identificação e exploração dessas oportunidades. Além disso, autores como Eisfeldt, Lustig e Zhang (2016) integram essa discussão referindo-se ao acúmulo de experiências como forma de êxito para potencialização de práticas inovadoras em ações futuras. Podemos averiguar esses argumentos no relato de um dos entrevistados:

[...] Até porque, esse mercado de jogos mobile que é denominado de external Business development é um segmento muito volátil, e exige que o empreendedor e/ ou desenvolvedor conheça bem esse mercado. Então, é necessário que a gente adquira espírito inovador e tenha boas parcerias. Nós precisamos obter uma capacidade de identificar o que há de novo no mercado e consecutivamente novos segmentos para esse mercado. Então, devemos combinar as oportunidades tecnológicas aos novos recursos ou aos recursos já existentes, em maneiras originais e criativas [...]. (E1 - p.1-2) [grifo nosso]

Nesse segmento de negócio, o empreendedor e o desenvolvedor de jogos precisam ter conhecimento especializado com respeito a tendências do mercado, demandas levantadas pelos jogadores e produção dos jogos do segmento mobile . Isso se coaduna com a definição

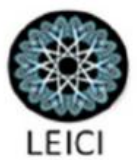


proposta no estudo de Gao, Krogstie e Zang (2016), o qual diz respeito ao fato de que para se produzir o jogo é necessário antes direcionar os objetivos para atividades intencionalmente articuladas que possam resultar em sucesso, a exemplo do Pokémon Go que marcou uma nova era para os novos modelos de interação com jogos eletrônicos voltados para smartphones.

\begin{abstract}
Bom, ao projetar um jogo, o desenvolvedor busca criar ferramentas que permitam uma melhor interação entres gamers, onde eles possam sentir-se atraídos por um universo mesmo que online, porém que o possibilite interagir com grupos de usuários que se identificam, em particular com aquele universo. Um exemplo bem conhecido é o Pokemom Go que usou o jogo mobile como ferramenta de fácil utilização para os vários públicos, especialmente os mais jovens, incentivando-os a visitar mais ou a passar mais tempo em espaços abertos, levando uma geração Y de jovens a valorizar lugares e ambientes naturais. Essa é uma ação que o jogo mobile traz para o subconsciente do indivíduo de modo intuitiva para apreciação do meio ambiente. Então, de maneira sistemática e analítica, a gente pode abordar o processo de desenvolvimento de jogos, apesar de ser um processo que exige muita criatividade analiticamente com medições e processos bem definidos, e isso é crucial para conseguir trabalhar com esse tipo de demanda $(\mathrm{E} 1-\mathrm{p} .2)$ [grifo nosso].
\end{abstract}

Buscar oportunidades em negócios que envolvem capacitação tecnológica, criatividade e inovação pode resultar na acumulação de experiências diversificadas e diferenciadas de segmentos de mercado tradicionais. O estudo de Edwards-Schachter et al. (2015) corrobora com essa visão ao destacar o perfil adequado de um empreendedor envolvido em segmentos de negócios direcionados para o mercado de produtos tecnológicos de alto valor agregado. Os autores acrescentam que ele tende a produzir ideias úteis para auxiliar na exploração de oportunidades em novos mercados e desenvolver comportamento inovador, em que são identificadas lacunas de mercado não atendidas ou segmentos parcialmente atendidos, com destaque para a combinação de recursos tecnológicos potencializados por meio de práticas inovadoras, o que pode envolver operações relacionadas às mudanças ambientais e empreendimentos intensivos em criatividade.

\title{
5.2. Dimensão das Competências de Relacionamento
}

A Competência de relacionamento é caracterizada por habilidades integradas daquele empreendedor digitalmente conectado e globalizado, tecnicamente competente, aberto a desafios e dotado de um comportamento empreendedor que auxilia na qualidade do relacionamento interpessoal em empresas de base tecnológica, em que se busca aqueles que podem auxiliar na diferenciação e avaliação próprio êxito em comparação com os integrantes da sua rede de negócios.

O empreendedor avalia de forma estratégica os modos como serão desenvolvidos os relacionamentos e, para isso, criam iniciativas para trabalhar junto com a academia, onde os pesquisadores elaboram projetos de pesquisa e extensão direcionados para a área de games, desenvolvidos junto às empresa e submetidos a órgãos como CNPQ e FACEPE (SILVA; PAIVA JÚNIOR, 2017). Portanto, o relato a seguir vem a corroborar esse pensamento: 
Para o primeiro trimestre de 2017 a gente tem algumas teses de investimento que necessitam de pesquisas, então enviamos nossos projetos para professores da Universidade Federal de Pernambuco que tem grupos de pesquisa nesta área. Eles avaliam o projeto, submetem a CAPES, CNPq ou FACEPE, e se deferidos, colocam seus alunos mais engajados para trabalhar no projeto e consequentemente executar da melhor forma possível. Estrategicamente a gente vai tendo iniciativas no decorrer do ano que irão demandar e envolver essas pessoas $(\mathrm{E} 1-\mathrm{p} .3)$.

A interação entre empreendedor, universidade e instituto de pesquisa constitui uma tríplice hélice de relacionamento e troca de experiências e informações com a finalidade de buscar posicionamento no mercado. Desse modo, autores como Törnroos, Halinen e Medlin (2016) asseguram que essas relações contribuem para o mapeamento do mercado e ajudam o empreendedor a ter uma visão ampla do seu negócio, coletar informações para identificar problemas e tomar decisões assertivas. Por isso, Lodish, Morgan e Kallianpur (2002) sustentam que o empreendedor que busca levantar informações de mercado, mostra-se atento a espaços de demandas não atendidas.

A atuação dos dirigentes voltados para manter relacionamentos com as entidades representativas, a exemplo de Gedigames, Abragames e International Game Developers Association (IGDA), os conecta a redes organizacionais compostas de atores chave desse setor de negócios de alta tecnologia. Logo, tais dirigentes emulam confiança, comprometimento e respeitabilidade de modo a perenizar suas relações comerciais. Essas características podem ser identificadas no discurso de atores, que se segue:

Eu particularmente acredito que a indústria brasileira de games em nível de relacionamento, como um todo, ainda precisa melhorar muito. Porém, temos aqui no Brasil institutos e associações direcionados para área de jogos eletrônicos, justamente com a finalidade de unir esses atores/ desenvolvedores. Por exemplo, temos a Abragames que é uma associação brasileira de games e grupos de estudos como a Gedigames. E mesmo assim, comparado a outros países ainda estamos caminhando em passos curtos. Mas felizmente, se formos comparar a dez anos atrás, melhoramos muito, e espero que esse relacionamento aqui aumente ainda mais. Já aqui em Pernambuco é muito próximo ao quadro geral do Brasil. Quando falamos em relacionamento, chega a ter muitas similaridades (E1).

O International Game Developers Association - IGDA, por exemplo, é uma instituição que procura fazer com que os desenvolvedores de vários países se conheçam e troquem informações. O IGDA tem como objetivo unir a indústria internacional de games. Então, é essencial que criemos relacionamentos com esses atores para troca de experiências e fortalecer o mercado local. (E2 - p.5) [grifo nosso].

$\mathrm{O}$ relato sugere que relacionamentos em redes sociais contemplam processos de cooperação e revelam a capacidade de interatividade como características evidenciadas no comportamento de dirigentes de empresas de games. Além disso, a interatividade e a conectividade proporcionam ao dirigente um estreitamento das interações com seus parceiros por intermédio dos laços de confiança e credibilidade que são construídos com relacionamentos sólidos e eficazes entre tais atores de negócios. 


\title{
5.3. Dimensão das Competências Conceituais
}

As competências conceituais são caracterizadas por um empreendedor ágil e observador, capaz de reconhecer cenários de incerteza e arriscar-se sob eles. Logo, o aprendizado contínuo de compartilhar conhecimento e atitudes, desenvolve ações velozes e intuitivas orientadas para solução de problemas (ROMERO, USART \& OTT, 2014) .

\subsubsection{Raciocínio criativo}

Diante da magnitude do processo de inovação, a reflexão criativa como ação gerencial sempre obteve destaque no cenário acadêmico e tecnológico (MUZZIO, 2017). Por isso, pensar de forma criativa é algo inerente a todo indivíduo vinculado às práticas de desenvolvimento de jogos eletrônicos, sejam eles produzidos para desktop, console ou dispositivos móveis. Do ponto de vista empírico, o depoimento a seguir ilustra tal situação:

\begin{abstract}
Somos pressionados todo tempo a chegar com ideias criativas, mudar e produzir respostas a todo instante. Compartilhamos essas ideias e fazemos uma seleção criteriosa do que pode ser realmente proveitoso para o projeto. Por isso, gerar, elaborar, promover e implementar ideias criativas já é algo nosso. É uma característica que a gente desenvolve nesse segmento de mercado. Acredito que algumas pessoas até nascem com essa característica, mas a maioria desenvolve. Eu particularmente desenvolvi esse talento na academia, e tudo que vejo ou leio me inspira para algo novo. Eu aprendi a pensar com criatividade na academia e estou aprimorando esta habilidade no mercado tecnológico dos games (E1 - p.5).
\end{abstract}

Considerando os traços de personalidade que englobam o comportamento e as características dos dirigentes de empresas de jogos mobile, as habilidades dos empreendedores de jogos mobile são descritas pelo entrevistado (E1) destacando a criatividade como aspecto relevante para o desenvolvimento e compartilhamento de novas ideias. Corroborando com o estudo de Múzzio (2017), em que podemos observar no respondente que a criatividade não é algo que vem por acaso. A criatividade é uma condição necessária para se alcançar vantagem competitiva em um cenário de inovação. Logo, com base nesse comportamento, a criatividade é descrita por Dong et al., (2017), EdwardsSchachter (2015), Frederiksen e Knudsen (2017), Fung (2017), Lameras et al., (2015) e Lampel e Germain (2016) como uma habilidade desenvolvida por um líder que empenha-se para adaptar-se a mudanças tecnológicas.

Para se raciocinar de forma criativa, é necessário que o empreendedor compartilhe suas ideias com seus interagentes como forma de suprir suas necessidades de otimização na condução dos projetos, entretanto habilidades desenvolvidas, como: flexibilidade cognitiva e visão compartilhada, são consideradas competências emergentes neste setor (FREDERIKSEN; KNUDSEN, 2017).

\subsubsection{Lidando com os riscos}

Ao tratar de cenários de incerteza, o empreendedor ao perceber situações de risco, se desdobra para manter o controle interno livre das ameaças e processos de perda de ativos

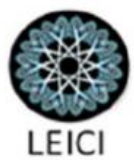


financeiros, a exemplo da carga tributária e fluxo de caixa. Por isso, o cenário de jogos mobile permite-nos indagar sobre qual é a percepção dos dirigentes com respeito às ameaças existentes no universo dos negócios e como controlar e reduzir os riscos nessas organizações.

Como a maioria dos riscos que corremos são voltados para parte tributária e financeira, nós tentamos mapear essas situações de risco e trabalhamos em mitigar esse risco de fluxo de caixa a todo tempo da melhor forma possível, porque quando houver um projeto maior que o esperado e caso haja algum atraso na sua finalização ou entrega, ou o cliente decidir rescindir o contrato, ou o dólar cair muito, ou até mesmo alguma tributação que não entendemos, devemos estar preparados $(\mathrm{E} 1-\mathrm{p} .5)$ [grifo nosso].

As observações de autores como Mills e Reiss (2017) se coadunam com as evidências empíricas apresentadas e ilustradas com o recorte sobre risco, confiança e suas evidências regulares em setores criativos, pois em tais setores ocorre maior índice de mudanças nas relações de trabalho, tornando as operações de mercado mais subjetivas e voláteis. Disso, emerge das narrativas dos dirigentes a mitigação de riscos usada para controlar as ameaças.

\subsection{Dimensão das Competências Administrativas}

As competências administrativas são caracterizadas por um empreendedor que de maneira eficiente se desdobra para fortalecer seu negócio. Utiliza-se de suas potencialidades para liderar de forma positiva e criativa com alto desempenho e motivação das pessoas.

\subsubsection{Liderança}

A liderança vem sendo fator determinante para o comportamento empreendedor, envolvendo as práticas organizacionais direcionadas para um ambiente de aprendizagem e criatividade. Por isso, o esforço por se desdobrar em mecanismos de planejamento, organização, comando, motivação, delegação e controle (MAN; LAU, 2000) refletem uma característica peculiar do empreendedor de jogos mobile.

Ter experiência e tempo disponível para usar a criatividade é primordial para um bom planejamento. Por isso quando vamos trabalhar no planejamento de determinado projeto, sempre procuramos engajar aqueles mais experientes e abrir pautas para críticas e sugestões da equipe, o que nos possibilita um ambiente de colaboração e criatividade. Nesse ambiente de liberdade, a própria equipe se organiza para fazer as tarefas e o produtor apenas define quem vai fazer determinada tarefa, o que não é necessariamente uma regra (E2 - p.5-6) [grifo nosso].

Foram evidenciadas as questões de expertise tanto dos dirigentes dos empreendimentos, quanto dos colaboradores que atuam em suas equipes, com base em experiências prévias desenvolvidas naquele segmento do mercado de games. Portanto, essas experiências possibilitam ao líder ter certo grau de flexibilidade sobre gestão da equipe, operando com atividades efetivadas por meio de participação colaborativa e promovendo o consenso entre os parceiros implicados no processo de tomada de decisão, além de recorrer a mecanismos que auxiliem a motivar tal equipe, tornando essas características recorrentes de

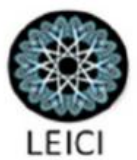


uma liderança transformacional. Assim, ao mesmo tempo em que se oferece um ambiente aberto e tolerante, também torna tal espaço de produção um local de desenvolvedores propícios à criatividade (DONG et al., 2017).

\subsection{Dimensão das Competências Estratégicas}

O desempenho de habilidades empreendedoras que envolvem planejar estrategicamente está aliado à tomada de decisão em curto e médio prazo, tendo em vista atingir os objetivos de longo prazo. Essa perspectiva de planejar estrategicamente está aliada à capacidade de estabelecer cenários que possibilitem a ação empreendedora por meio do desenvolvimento de planos de negócios.

Levando em consideração que o mercado de games é volátil e por isso temos que estar preparados para mudar no que for preciso. Isso envolve tomada de decisão de nível estratégico entre os sócios para acompanhar as tendências do mercado de jogos mobile em tempo real, e manter uma rede networking com parceiros para troca de informações sobre as novidades do mundo corporativo do audiovisual (E2).

Essa narrativa corrobora com a afirmação de França et al. (2017) que certifica que um planejamento estratégico bem estruturado envolve um modelo de negócios desenvolvido para alcançar uma visão sistêmica. Para cada estratégia adotada, em se tratando de um cenário volátil como o mercado tecnológico, existem diferentes possibilidades de gestão de o planejamento alcançar os resultados esperados. Logo, o empreendedor utiliza suas habilidades estratégicas para adotar possíveis soluções na busca de melhorias significativas no desempenho do negócio. Assim, os usos de mecanismos de oferta e entrega dos serviços estão aliados ao planejamento estratégico como ferramenta para potencializar uma nova estrutura da cadeia de fornecimento de serviços.

\subsection{Dimensão das Competências de Comprometimento}

O empreendedor tem compromisso com o negócio em proporção semelhante aos seus compromissos pessoais. Tal constatação confirma o estudo de Lapointe e Vandenberghe (2017), que asseguram serem as intenções, os sentimentos, os desejos e as motivações pessoais, vinculados à necessidade de expansão e manutenção do negócio, essenciais para o benefício da organização.

\footnotetext{
Apesar dos obstáculos encontrados na gestão do empreendimento e de algumas situações de insucesso, com trabalho e ações estratégicas sempre consegui ultrapassar dificuldades. Para isso eu tinha sempre um plano B no caso de algo que desse errado, e ainda procuro ser resiliente pra superar alguns problemas desse tipo (E1).
}

Estabelecer e manter certo grau de comprometimento neste contexto de dificuldades parece ser fator primordial de apresentação das intenções do empreendedor conduzidas para o aperfeiçoamento desse tipo de negócio, de si próprio e das equipes. Isso garante o fortalecimento do compromisso de a ação empreendedora se transformar em credibilidade como reflexo do senso de responsabilidade presente na capacidade de crescimento e na força

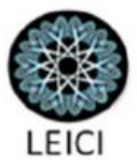


para trabalhar continuamente em meio às dificuldades enfrentadas por tal dirigente em seu cotidiano (MELLO; LEÃO; PAIVA JÚNIOR, 2006).

Esse movimento fortalecido pelo comprometimento com a ação empreendedora se transforma em credibilidade e se reflete na manutenção de um relacionamento de confiança entre todos os envolvidos (PAIVA JÚNIOR; FERNANDES, 2012; ROMERO, USART \& OTT, 2014).

\subsection{Dimensão das Competências de Equilíbrio Trabalho/Vida Pessoal}

Ao observar a existência de fatores do cotidiano, o estudo realizado por Mello, Leão e Paiva Júnior (2006) sugere que as competências referentes ao equilíbrio entre vida pessoal e profissional compreendem a rotina das atividades de forma bem humorada e como um jogo desafiante. Desse modo, o empreendedor declara que em algumas circunstâncias o equilíbrio entre vida pessoal e profissional se tornam complementares, porém ainda são concorrentes em termos de prioridades.

Normalmente, trabalho mais de doze horas os cinco dias da semana, e a vida pessoal deixo para o fim de semana. No final de semana as chances de eu trabalhar é quase zero, se tiver que trabalhar será por uma ocasião muito especial ou por algum motivo específico de algo que aconteceu, uma emergência, mas de qualquer forma termina sendo muito mais trabalho que a vida pessoal. E a minha prioridade acaba sendo maior para trabalho, apesar de que tento conciliar de forma a serem complementares (E1).

Conforme o relato, o dirigente ainda dá prioridade ao trabalho, porém, percebe que é necessário compreender sua rotina profissional de forma bem humorada para que desenvolva atividades alheias ao cotidiano da empresa. Postura essa reconhecida por Colombo e Grilli (2005), Alegre e Pasamar (2018) e Nieuwenhuis e Kossek (2018), levando em consideração que o potencial do capital humano desenvolvido para empresas de base tecnológica não é apenas um instrumento para a riqueza e crescimento organizacional, mas este capital humano também pode ser afetado positiva ou negativamente quando os esforços são exauridos para os domínios econômicos e de gestão da empresa, o que implica em prejuízos para vida pessoal.

A discussão levanta um diálogo organizacional direcionado para a valorização do tempo destinado pela equipe em sua vida pessoal e por esses serem compartilhadas para o trabalho. Isso inclui o ato de dar liberdade de horário e o compartilhamento de informações particulares sobre suas prioridades pessoais e seu papel de vida na organização.

\section{Considerações finais}

Diante da necessidade de apresentar evidências conclusivas dos resultados gerados nesse estudo, fruto do esforço analítico que demonstrou aspectos emergentes que retomam o questionamento inicial da pesquisa: Que competências empreendedoras emergem do comportamento de líderes que dirigem empresas de jogos mobile no Arranjo Portomída?

O Empreendedorismo envolve a produção e comercialização de jogos mobile a partir de sete competências empreendedoras distintas: oportunidade, relacionamento, conceitual,

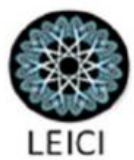


administrativa, estratégica, comprometimento e equilíbrio trabalho/vida pessoal (MELLO; LEÃO; PAIVA JÚNIOR, 2006). Essas competências são reflexos do comportamento de empreendedores comprometidos com o mercado de jogos mobile.

Existem comportamentos específicos que emergem de cada dimensão de competência empreendedora. Desse modo, dentre as sete áreas de competências apresentadas no estudo, algumas delas apresentam maior incidência com respeito à liderança desses dirigentes. Assim, competências como de relacionamento, conceituais e administrativas se destacam por serem identificadas com maior ocorrência e sendo primordiais para incrementar o desempenho de empresas especializadas em jogos mobile.

Em relação à Competência de Relacionamento, destacam-se a interatividade, a conectividade e a ação em rede organizacional por terem sido representativos dessa área de competência e se mostrarem relevantes para a construção das redes de relacionamento em situações críticas de negociação com os parceiros estratégicos. Portanto, essas competências contribuem para o processo de inovação, ao favorecer o aperfeiçoamento de boas práticas como dinamização da criatividade, intercâmbio de conhecimentos e aprendizado contínuo desses dirigentes e suas equipes de colaboradores estruturas em redes de negócio e tecnologia.

Dentre os fatores condicionantes observáveis no meio empreendedora de empresas de jogos mobile, a formação acadêmica emerge como fator predominante na capacitação de seus dirigentes. Além disso, a influência de fatores tecnológicos ocorre no processo de expansão das Tecnologias da Informação e Comunicação e do poder de penetrabilidade dos jogos mobile em várias áreas da vida humana, possibilitando a atuação mercadológica desses empreendedores. Assim, este estudo contribui com a discussão sobre competências empreendedoras no escopo das Indústrias Criativas, destacando as competências relacionais, conceituais e administrativas para lidar com cenários de incerteza, cujo insumo principal é a criatividade.

Para um maior entendimento acerca de competências empreendedoras no escopo das Indústrias Criativas, sugerimos que pesquisas futuras sejam realizadas em Arranjos Produtivos de outras localidades do território nacional. Também argumentamos a favor da necessidade de investigação do constructo das competências empreendedoras em outras áreas das Indústrias Criativas, tais como cinema, música, design, moda, audiovisual, software, publicidade.

\section{Referências}

ABATECOLA, G.; ULI, V. Entrepreneurial competences, liability of newness and infant survival: Evidence from the service industry. Journal of Management Development, v. 35, n. 9, p. 1082-1097, 2016.

ALBUQUERQUE, A. da. R. P.; TEIXEIRA, R. M. O Processo de Identificação e Exploração de Oportunidade Empreendedora com base no Modelo de Aprendizagem Organizacional

4i. Revista de Ciências da Administração, v. 18, n. 44, p. 25-37, 2016.

ALEGRE, J.; PASAMAR, S. Firm innovativeness and work-life balance. Technology

Analysis \& Strategic Management, v. 30, n. 4, p. 421-433, 2018.
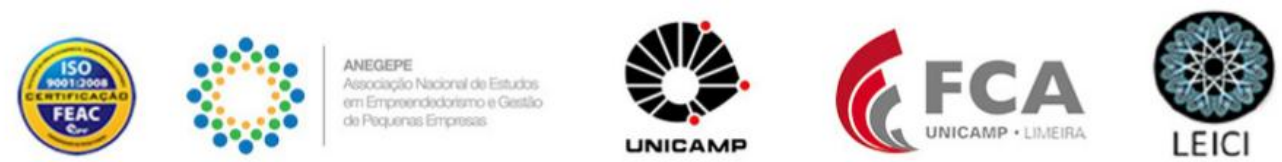
ANDRADE, T. A. B. de; CASTILLO, L. A. G.; ARRUDA, A. O.; AZEVEDO, G.;

MATOSO, A. C.; BRITO, M. A. de F. Design Driven Innovation para Economia Criativa: em busca do fomento de inovação de significado para portomídia. Blucher Design Proceedings, v. 1, n. 4, p. 2852-2863, 2014.

BADEN-FULLER, C.; HAEFLIGER, S. Business models and technological innovation.

Long range planning, v. 46, n. 6, p. 419-426, 2013.

BARDIN, L. Análise de Conteúdo. São Paulo: Edições 70, 2011.

COLOMBO, M. G.; GRILLI, L. Founders' human capital and the growth of new technology-

based firms: A competence-based view. Research policy, v. 34, n. 6, p. 795-816, 2005.

CRESWELL, J. W. Projeto de pesquisa: métodos qualitativo, quantitativo e misto. 3 ed.

Porto alegre: Artmed, 2010.

DAVIDSON, Elizabeth; VAAST, Emmanuelle. Digital entrepreneurship and its sociomaterial enactment. In: System Sciences (HICSS), 2010 43rd Hawaii International Conference on. IEEE, 2010. p. 1-10.

DONG, Y.; BARTOL, K. M.; ZANG, Z-X.; LI, C. Enhancing employee creativity via individual skill development and team knowledge sharing: Influences of dual-focused transformational leadership. Journal of Organizational Behavior, v. 38, n. 3, p. 439-458, mar. 2017.

EDWARDS-SCHACHTER, M.; GARCIA-GRANERO, A.; SÁNCHEZ-BARRIOLUENGO, M.; QUESADA-PINEDA, H.; AMARA, N. Disentangling competences: Interrelationships on creativity, innovation and entrepreneurship. Thinking Skills and Creativity, v. 16, p. 27-39, 2015 .

EISFELDT, A. L.; LUSTIG, H. N.; ZHANG, L. Risk and Return in Segmented Markets with Expertise. SSRN, 2016.

ERTURKOGLU, Z.; ZHANG, J.; MAO, E. Pressing the Play Button: What Drives the Intention to Play Social Mobile Games? International Journal of E-Business Research (IJEBR), v. 11, n. 3, p. 54-71, 2015.

FRANÇA, C. L.; BROMAN, G.; ROBERT, K-H.; BASILE, G.; TRYGG, L. An approach to business model innovation and design for strategic sustainable development. Journal of Cleaner Production, v. 140, p. 155-166, 2017.

FREDERIKSEN, M. H.; KNUDSEN, M. P. From Creative Ideas to Innovation Performance: The Role of Assessment Criteria. Creativity and Innovation Management, v. 26, n. 1, p. 60-74, mar. 2017.

FUNG, A. The Impact of the Rise of Mobile Games on the Creativity and Structure of the Games Industry in China. In: JIN, D. Y. Mobile Gaming in Asia. Springer Netherlands, 2017.

GALANAKIS, K.; GIOURKA, P. Entrepreneurial path: decoupling the complexity of entrepreneurial realisation. International Journal of Entrepreneurial Behaviour and Research, v. 23, n. 2, 2017.

GAO, S.; KROGSTIE, J.; ZANG, Z. The Effect of Flow Experience and Social Norms on the Adoption of Mobile Games in China. International Journal of Mobile Human Computer Interaction (IJMHCI), v. 8, n. 1, p. 83-102, 2016.

HARTLEY, J. Creative Industries. London: Blackwell, 2005.
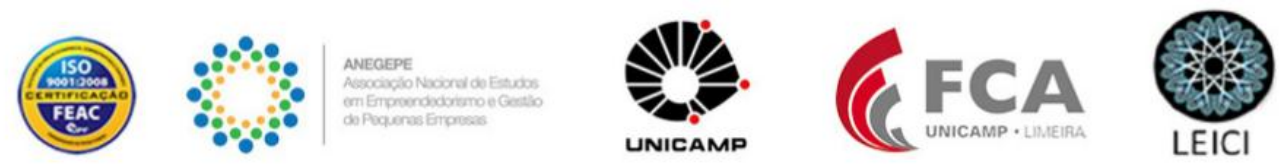
JAIN, R. K. Entrepreneurial competencies: a meta-analysis and comprehensive conceptualization for future research. Vision, v. 15, n. 2, p. 127-152, 2011.

KOIVISTO, A.; MERILAMPI, S.; SIRKKA, A. Mobile games individualise and motivate rehabilitation in different user groups. International Journal of Game-Based Learning (IJGBL), v. 5, n. 2, p. 1-17, 2015.

LAKATOS, E. M.; MARCONI, M. de A. Metodologia científica. 5. ed. São Paulo: Atlas, 2010.

LAMERAS, P.; TSIATSOS, T.; PETRIDIS, P.; TOLIS, D.; LIAROKAPIS, F.;

ANASTASIADOU, D.; PROTOPSALTIS, A.; HENDRIX, M.; ARNAB, S. Creative thinking experimentations for entrepreneurship with a disruptive, personalised and mobile game-based learning ecosystem. In: International Conference on Interactive Mobile Communication Technologies and Learning (IMCL), 2015, Grécia. Anais... Grécia: IMCL, 2015.

LAMPEL, J.; GERMAIN, O. Creative industries as hubs of new organizational and business practices. Journal of Business Research, v. 69, n. 7, p. 2327-2333, jul. 2016.

LAPOINTE, É.; VANDENBERGHE, C. Supervisory mentoring and employee affective commitment and turnover: The critical role of contextual factors. Journal of Vocational Behavior, v. 98, p. 98-107, 2017.

LEFÈVRE, F.; LEFÈVRE, A. M. V. O discurso coletivo. Um novo enfoque em pesquisa qualitativa (Desdobramentos). 2. ed. Caxias do Sul, RS: Educs, 2005.

LELOUX, M.; POPESCU, F.; KOOPS, A. New Skills for Entrepreneurial Researchers. In: KANTOLA, J.; BARATH, T.; NAZIR, S.; ANDRE, T. Advances in Human Factors, Business Management, Training and Education. Springer International Publishing, 2017. LODISH, L. M.; MORGAN, H.; KALLIANPUR, A. Entrepreneurial Marketing: lessons from Wharton's pioneering MBA course. John Wiley \& Sons, 2002.

MAN, T. W. Y.; LAU, T. Entrepreneurial competencies of SME owner/managers in the Hong Kong services sector: a qualitative analysis. Journal of Enterprising Culture, v.8, n.3, p. 235-254, set. 2000.

MELLO, S. C. B. LEÃO, A. L. M. S. PAIVA JÚNIOR, F. G. Competências empreendedoras de dirigentes de empresas brasileiras de médio e grande porte que atuam em serviços da nova economia. Revista de Administração Contemporânea, v. 10, n. 4, p. 47-69. out./ dez. 2006. MIETZNER, D.; KAMPRATH, M. A competence portfolio for professionals in the creative industries. Creativity and Innovation Management, v. 22, n. 3, p. 280-294, 2013. MILLS, R. W.; REISS, D. R. The role of trust in the regulation of complex and high-risk industries: the case of the US Federal Aviation Administration's voluntary disclosure programs. In: SIX, F.; VERHOEST, K. Trust in Regulatory Regimes. United States: Edward Elgar Publishing, 2017.

MINAYO, M. C. S. O desafio do conhecimento: pesquisa qualitativa em saúde. 12 ed. São Paulo: Hucitec, 2010.

MUZZIO, H. Indivíduo, Liderança e Cultura: Evidências de uma Gestão da Criatividade/ Individual, Leadership and Culture: Evidence of Creativity Management. Revista de Administração Contemporânea, v. 21, n. 1, p. 107-124, 2017.

NIEUWENHUIS, R.; KOSSEK, E. E. Work-life balance in times of recession, austerity and beyond. 2018. 
PAIVA JÚNIOR, F. G.; FERNANDES, N. C. M. A contribuição da competência relacional do empreendedor para aperfeiçoar a qualidade de relacionamento entre empresas de base tecnológica. RAI Revista de Administração e Inovação, v. 9, n. 3, p. 53-76, 2012.

PARKER, R.; COX, S.; THOMPSON, P. How technological change affects power relations in global markets: remote developers in the console and mobile games industry. Environment and planning A, v. 46, n. 1, p. 168-185, 2014.

PARKER, S. K.; BINDL, U. K. Proactivity at work: making things happen in organizations. Londres: Routledge, 2016.

PORTOMÍDIA. Áreas de atuação: Games. Recife, 2015. Disponível em:

<http://www.portomidia.org/games.php>. Acesso em: 4 nov. 2015.

PORTO DIGITAL. Chamada pública para incubação de empreendimentos da Economia

Criativa no Porto Digital. Disponível em: www2.portodigital.org. Recife, 2012. Acesso em:

20 Jan. 2017.

ROMERO, M; USART. M; OTT, M. Can serious games contribute to developing and sustaining 21st century skills? Games and Culture, v.10, n. 2, p. 148-177, 2014.

SEOK. S; DACOSTA. B. Predicting video game behavior: an investigation of relationship between personality and mobile game play. Games and Culture, v. 10, n. 5, p. 481-501, 2015.

SILVA, A. D. F.; PAIVA JÚNIOR, F. G. A influência da rede de negócios na produção de bens simbólicos em empresas de softwares no cluster porto digital. Desenvolve Revista de Gestão do Unilasalle, v. 6, n. 1, p. 45-66, 2017.

SUSSAN, Fiona; ACS, Zoltan J. The digital entrepreneurial ecosystem. Small Business

Economics, v. 49, n. 1, p. 55-73, 2017.

TÖRNROOS, J-A.; HALINEN, A.; MEDLIN, C. J. Dimensions of space in business network research. Industrial Marketing Management, jun. 2016.

VON BRIEL, Frederik; DAVIDSSON, Per; RECKER, Jan. Digital technologies as external enablers of new venture creation in the IT hardware sector. Entrepreneurship Theory and Practice, v. 42, n. 1, p. 47-69, 2018.

YIN, R. K. Estudo de caso: planejamento e métodos. 3. ed. Porto Alegre: Bookman, 2005. 